\title{
Visual Outcomes After Cataract Surgery: Multifocal Versus Monofocal Intraocular Lenses
}

\author{
Sunil Shah, MD; Cristina Peris-Martinez, MD, PhD; Thomas Reinhard, MD; Paolo Vinciguerra, MD
}

\section{ABSTRACT}

PURPOSE: To evaluate visual outcomes, spectacle independence, and quality of life among nonastigmatic and astigmatic patients who received AcrySof IQ ReSTOR toric or nontoric multifocal intraocular lenses (IOLs) (Alcon Laboratories, Fort Worth, TX) compared with those who received commercially available nontoric monofocal IOLs after bilateral cataract removal.

METHODS: This randomized, patient- and observertechnician-masked study was conducted at 20 sites in Europe. Patients were randomized to receive monofocal (nontoric only) or multifocal (nontoric or toric, as needed) IOLs. Primary efficacy endpoints included percentage of patients achieving binocular uncorrected distance and near acuity of 0.1 logMAR or better (20/25 Snellen), spectacle independence, and scores on the National Eye Institute Refractive Error and Quality of Life questionnaire domains. Safety endpoints included adverse events and refractive error within 0.5 and 1.0 diopters.

RESULTS: In the multifocal group ( $n=108$ ) versus the monofocal group $(n=100)$, significantly more patients achieved uncorrected distance and near acuity of 0.1 logMAR or better (45.7\% vs 2.1\%; $P<.0001)$ and spectacle independence (73.3\% vs $25.3 \% ; P<.0001)$ at 6 months. The percentage of patients who achieved uncorrected distance visual acuity of 20/40 or better at 6 months was $92 \%$ in the multifocal group and $97 \%$ in the monofocal group. National Eye Institute Refractive Error and Quality of Life scores were significantly better for dependence on correction in the multifocal group $(P<.0001)$ and for glare in the monofocal group $(P$ $=.0157)$; other domain scores were similar between groups. No significant trends in study device-related adverse events were observed.

CONCLUSIONS: Monofocal and multifocal IOLs provided good clinical outcomes. More patients receiving multifocal IOLs attained better uncorrected visual acuity at a range of distances and spectacle independence compared with patients who received monofocal IOLs. Monofocal IOLs were associated with better patientreported scores for glare compared with multifocal IOLs; however, scores for patient satisfaction were significantly better in the multifocal group.

[J Refract Surg. 2015;31(10):658-664.]

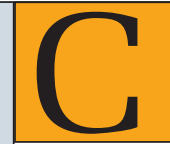

ataract is a common, vision-altering condition that affects 36 million people in Western Europe and is projected to affect approximately 30 million people in the United States by the year 2020. ${ }^{1}$ Implantation of a monofocal intraocular lens (IOL) after surgical removal of cataract via phacoemulsification is the standard of care in the Western world. ${ }^{2}$ Although monofocal IOLs result in excellent distance acuity, patients usually require corrective spectacles

From Midland Eye, Solihull, United Kingdom (SS); Fisabio Oftalmología Médica, Valencia, Spain (CP-M); Eye Center, University of Freiburg, Freiburg, Germany (TR); and Istituto Clinico Humanitas, Humanitas Eye Center, Milan, Italy (PV).

(c) 2015 Shah, Peris-Martinez, Reinhard, et al; licensee SLACK Incorporated. This is an Open Access article distributed under the terms of the Creative Commons Attribution-NonCommercial 4.0 International (http://creativecommons.org/licenses/by-nc/4.0). This license allows users to copy and distribute, to remix, transform, and build upon the article non-commercially, provided the author is attributed and the new work is non-commercial.

Participating Investigators: Antione Brezin (Hôpital Cochin), Maxence Bonne (Cabinet d'Ophthalmologie des Flandres), Beatrice Cochener (Hôpital Morvan), Manfred Tetz (Augentagesklinik Spreebogen Berlin), Thomas Reinhard (Universitätsklinikum Freiburg), Albert Augustin (Städtisches Klinikum Karlsruhe), Helmut G. Sachs (Krankenhaus Dresden-Friedrichstadt, Städtisches Klinikum), Sunil Shah (Midland Eye Institute), Paolo Vinciguerra (Instituto Clinico Humanitas, Humanitas Cancer Center), Leonardo Mastropasqua (Ospedale Clinicizzato SS. Annunziata), Ugo Menchini (Azienda Osperdaliera Universitaria Careggi), K. F. Tjia (Isala Klinieken), A. A. Rulo (Oogziekenhuis Zonnestraal), B. L. Zijlmans (Stichting Oogziekenhuis), A. J. Van Hogerwou (Gelre Ziekenhuizen), Alfonso Arias-Puente (Fundacion Hospital, Alcorcon), Cristina Peris-Martinez, (Fundación Oftalmológica Mediterráneo), Javier Mendicute (Hospital Donostia), José Angel Cristóbal (Hospital Universitario), and Isabel Jordi Solsona (Hospital Universitari del Sagrat Cor).

Submitted: January 29, 2015; Accepted: June 8, 2015

Supported by Alcon Research, Ltd. The study sponsor participated in study design and data analysis and agreed with the decision to submit the manuscript for publication.

The authors have no financial or proprietary interest in the materials presented herein.

The authors thank Heather D. Starkey, PhD, of Complete Healthcare Communications, Inc., Chadds Ford, PA, for medical writing assistance; Dr. Fabrizio I. Camesasca for his thorough review of the manuscript; and Dr. Manoj Venkiteshwar for his contributions to manuscript preparation.

Trial Registration: ClinicalTrials.gov, identifier NCT01290068; registered February 2011

Correspondence: Sunil Shah, MD, Midland Eye, 50 Lode Lane, B91 2AW, Solihull, United Kingdom. E-mail: sunilshah@doctors.net.uk

doi:10.3928/1081597X-20150611-01 
for vision at near and intermediate distances and residual astigmatic error, if any. ${ }^{3,4}$ Astigmatism should be managed during cataract surgery and IOL implantation to minimize postoperative dependence on spectacles. ${ }^{5}$ Incomplete restoration of visual acuity in patients implanted with monofocal or multifocal IOLs has been associated with limiting factors contributing to quality of life, such as reading and maintaining hobbies that require near vision. ${ }^{6}$

Multifocal IOLs could decrease patients' need for spectacles by providing good vision across a range of distances (near, intermediate, and far). Newer multifocal IOL designs improve patient vision and achieve acceptable patient satisfaction. ${ }^{7}$ The AcrySof IQ ReSTOR (Alcon Laboratories, Fort Worth, TX) is a commercially available multifocal IOL for primary implantation in the capsular bag of the eye for visual correction of aphakia secondary to removal of a cataractous lens. ${ }^{8-10}$ This IOL combines a central apodized diffractive region for enhanced near vision, surrounded by a refractive region for distance vision. The AcrySof IQ ReSTOR toric IOL is a multifocal IOL that can address corneal astigmatism. ${ }^{5}$

The goal of this study was to evaluate and compare visual outcomes, spectacle independence, and patient vision-related quality of life following bilateral implantation of either commercially available monofocal IOLs or AcrySof IQ ReSTOR multifocal IOLs among patients undergoing cataract surgery.

\section{STUDY DESIGN}

\section{PATIENTS AND METHODS}

This was a phase 4 prospective, randomized, patient- and observer-technician-masked, comparative, 6-month follow-up study conducted in 20 centers in France, Germany, Italy, the Netherlands, Spain, and the United Kingdom between April 2011 and October 2012 (ClinicalTrials.gov Identifier: NCT01290068). The study protocol was approved by the ethics committees of all study centers, and the study was performed in compliance with the tenets of the Declaration of Helsinki. Informed consent was provided by all patients before study entry.

\section{Patients}

Study participants, aged 21 years or older, were previously diagnosed as having bilateral age-related cataracts and planned cataract removal using phacoemulsification with subsequent IOL implantation. Eligible patients were either nonastigmatic or were astigmatic with preoperative regular corneal astigmatism of 2.5 diopters (D) or less, with otherwise healthy eyes, and were available to undergo cataract removal in the second eye 6 weeks or less after the first eye surgery. Additionally, it was required that both eyes meet qualification criteria for onlabel implantation of the AcrySof IQ ReSTOR family of IOLs. Key exclusion criteria included previous corneal surgery or corneal reshaping, corneal abnormalities, conditions or diseases that contraindicated implantation of a toric IOL, or planned multiple procedures during phacoemulsification and IOL implantation surgery.

\section{TREATMENT}

Patients were randomized to receive either AcrySof IQ ReSTOR multifocal IOLs (nontoric or toric as required) or commercially available monofocal IOLs (nontoric only) on the date of the first operative visit before surgery in the first eye to be treated; patients were to receive bilateral implantation of either multifocal or monofocal aspheric IOLs. Patients in the multifocal IOL group received toric or nontoric models based on the magnitude of preoperative corneal astigmatism; patients in the monofocal IOL group received nontoric IOLs only. A web-based calculator that accounted for predicted IOL power as evaluated by biometry, preoperative keratometric values, surgically induced astigmatism, and incision placement was used to determine whether toric or nontoric IOLs were needed for patients receiving multifocal IOLs. If the calculator determined that a patient required a toric IOL, it also established the alignment. Cataract extraction and IOL implantation were performed according to the participating clinics' standard methods. Postoperative medications were provided to all patients according to the clinics' standard of care following routine cataract removal.

\section{EFFICACY ENDPOINTS AND ASSESSMENTS}

The three primary efficacy endpoints were percentage of patients achieving binocular uncorrected distance visual acuity and uncorrected near visual acuity $0.1 \operatorname{logMAR}$ or better (20/25 Snellen); spectacle independence (ie, not using or prescribed spectacles) at all distances; and National Eye Institute Refractive Error and Quality of Life instrument score (NEI RQL-42; range: 0 to 100 [higher score indicates a better outcome] $)^{11}$ in five dimensions: near vision, activity limitations, dependence on refractive correction (ie, glasses, bifocal lenses, magnifier, contact lenses), ${ }^{12}$ appearance, and satisfaction with correction.

The secondary efficacy endpoint was the cost of spectacles. An additional eight nonprimary NEI RQL42 dimensions (clarity of vision, expectation, far vision, diurnal fluctuation, glare, symptoms [eg, burning, itching, aching, dryness], ${ }^{12}$ worry, and suboptimal correction) were assessed as exploratory endpoints.

Visual acuity testing was performed at far $(4 \mathrm{~m})$, near $(40 \mathrm{~cm})$, and intermediate $(60 \mathrm{~cm})$ distances using 


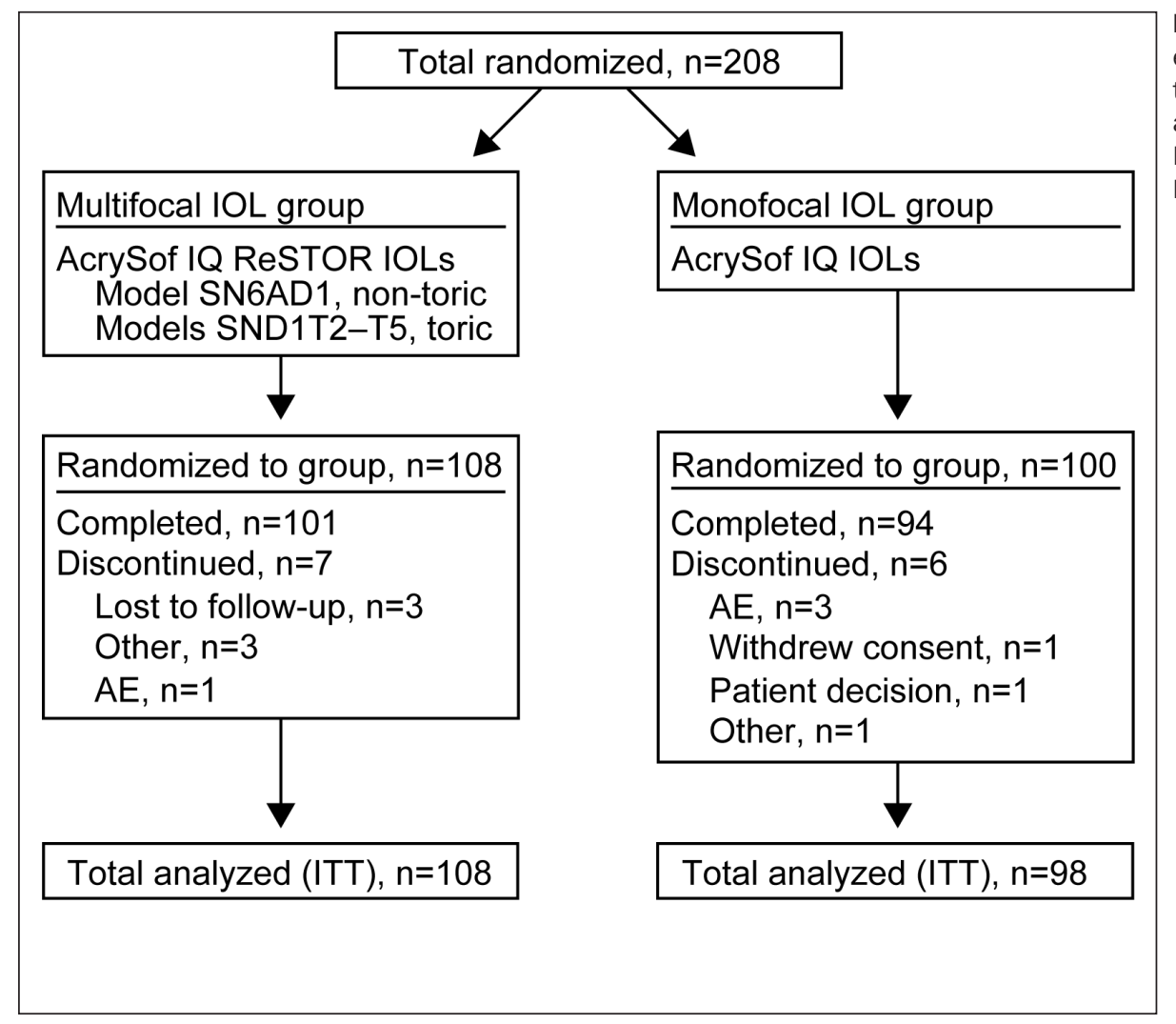

Figure 1. Patient disposition. $A E=$ adverse event; $\mathrm{IOL}=$ intraocular lens; $\mathrm{ITT}=$ intentto-treat; monofocal IOL $=$ commercially available nontoric IOLs; multifocal IOL $=$ AcrySof IQ ReSTOR nontoric or toric IOLs (Alcon Laboratories, Fort Worth, TX)

Early Treatment of Diabetic Retinopathy Study (ETDRS) charts at $100 \%$ contrast. Actual logMAR visual acuity was calculated using baseline logMAR visual acuity (the last line from which the patient correctly read 1 or more letters) and the number of letters read incorrectly.

Lens information (model, diopter power, and serial number) was documented separately from case report forms and was masked throughout the study to patients and the observer-technicians who measured visual acuity and refraction. Ophthalmologists performing IOL implantation were not masked.

\section{SAFETY ASSESSMENTS}

The incidence rates of adverse events, including surgical reintervention such as IOL replacement, explantation, or repositioning, were recorded intraoperatively and at postoperative day 1 and months 1,3 , and 6. Achievement of postoperative refractive error greater than $0.50 \mathrm{D}$ and greater than $1.0 \mathrm{D}$ at 6 months was also assessed.

\section{Data Analysis and Statistics}

Efficacy endpoints were analyzed in the intent-totreat population, defined as all patients who were randomized to a treatment group and to whom the randomized IOL was presented or implanted during the first eye surgery. Patients in the intent-to-treat population were grouped according to the randomly assigned treatment group (ie, multifocal or monofocal IOL). The proportion of patients achieving binocular uncorrected distance acuity and uncorrected near visual acuity of 0.1 $\operatorname{logMAR}$ or better (20/25 Snellen) and the proportion of patients with spectacle independence in each group at the 6-month visit were compared using logistic regression models with binary response that included country, implantation group, and preoperative astigmatism as covariates. The NEI RQL-42 scores at the 6-month visit for each group were compared using an analysis of covariance model with country, implantation group, preoperative astigmatism, and baseline dimension scores as covariates. Missing primary endpoint data were accounted for using the last observation carried forward.

The total cost of spectacles purchased (frames plus lenses) in all patients was compared between groups using a nonparametric Kolmogorov-Smirnov test. If total cost was missing for a spectacle-independent patient, 0 euros was imputed. If total cost was missing for a spectacle-dependent patient, the mean cost for all spectacle-dependent patients in that group was imputed. The summary statistics for spectacle-dependent patients were based on those spectacle-dependent patients who provided a cost or reimbursement amount. Analysis of the five primary NEI RQL-42 domains was performed using the Hommel multiple testing correc- 


\begin{tabular}{|c|c|c|c|}
\hline \multicolumn{4}{|c|}{$\begin{array}{c}\text { TABLE } 1 \\
\text { Patient Demographics, Intent-to-Treat Population }\end{array}$} \\
\hline Characteristic & Multifocal Group $(n=108)$ & Monofocal Group $(n=98)$ & Total $(n=206)$ \\
\hline Mean \pm standard deviation age, years & $70.0 \pm 8.3$ & $70.8 \pm 7.8$ & $70.4 \pm 8.1$ \\
\hline \multicolumn{4}{|l|}{ Age category, n (\%) } \\
\hline 21 to 59 years & $13(12.0)$ & $7(7.1)$ & $20(9.7)$ \\
\hline 60 to 69 years & $40(37.0)$ & $36(36.7)$ & $76(36.9)$ \\
\hline 70 to 79 years & $40(37.0)$ & $45(45.9)$ & $85(41.3)$ \\
\hline 80 years or older & $15(13.9)$ & $10(10.2)$ & $25(12.1)$ \\
\hline \multicolumn{4}{|l|}{ Sex, n (\%) } \\
\hline Male & $45(41.7)$ & $40(40.8)$ & $85(41.3)$ \\
\hline Female & $63(58.3)$ & $58(59.2)$ & $121(58.7)$ \\
\hline \multicolumn{4}{|l|}{ Race, n (\%) } \\
\hline White & $103(95.4)$ & 94 (95.9) & $197(95.6)$ \\
\hline Black or African American & $1(0.9)$ & $2(2.0)$ & $3(1.5)$ \\
\hline Asian & $3(2.8)$ & $2(2.0)$ & $5(2.4)$ \\
\hline American Indian or Alaska Native & $1(0.9)$ & 0 & $1(0.5)$ \\
\hline
\end{tabular}

tion procedure. All statistical analyses were performed with two-sided tests at a significance level of $5 \%$.

Safety analyses were assessed in the safety population, defined as all patients randomized to a treatment group who received one or more implanted IOL, and were coded using the Medical Dictionary for Regulatory Activities, version 14.0. Safety analysis was conducted according to the received IOL implantation groups; for patients who received one multifocal IOL and one monofocal IOL, safety analysis was based on the planned implantation group.

\section{Patients}

\section{RESULTS}

A total of 208 patients were randomized (multifocal IOL group, $\mathrm{n}=108$; monofocal IOL group, $\mathrm{n}=$ 100), 195 of whom completed the study (Figure 1). The safety and intent-to-treat populations each comprised 206 patients; treatment group sizes between safety and intent-to-treat populations varied because 3 patients who were randomized to receive multifocal lenses received monofocal lenses, and 1 patient who was randomized to receive monofocal lenses received multifocal lenses. However, all patients were eligible for both multifocal and monofocal IOLs and were not informed of their randomization group before surgery. Of the patients who received multifocal lenses, 86 received toric models and 19 received nontoric models. Patient age, sex, and race were similar between treatment groups (Table 1).

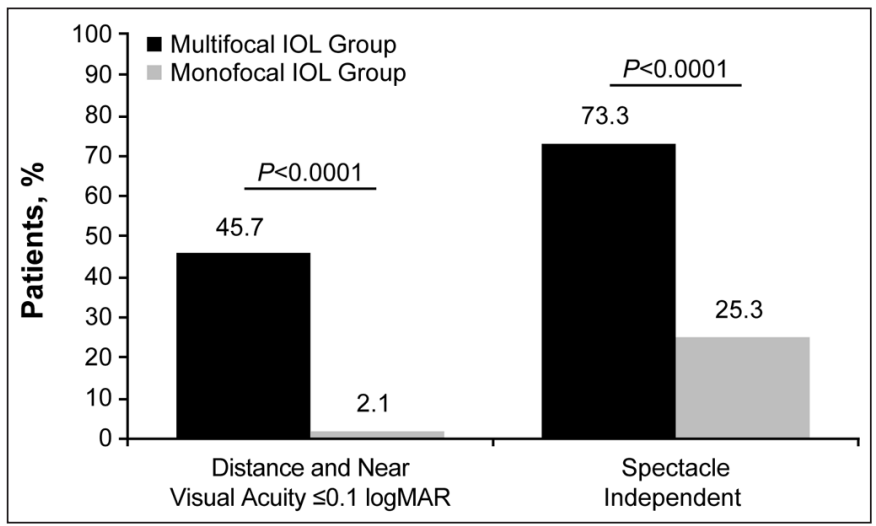

Figure 2. Percentages of patients who achieved binocular uncorrected distance and binocular uncorrected near visual acuity 0.1 logMAR or better (20/25 Snellen) and percentages of patients who were spectacle free at 6 months postoperatively. $\mathrm{IOL}=$ intraocular lens; monofocal $\mathrm{IOL}=$ commercially available nontoric IOLs; multifocal IOL = AcrySof IQ ReSTOR nontoric or toric IOLs (Alcon Laboratories, Fort Worth, TX).

\section{EFFICACY}

A significantly greater proportion of patients achieved both distance and near binocular uncorrected visual acuity (0.1 logMAR or better [20/25 Snellen] at the 6-month visit) in the multifocal IOL group (45.7\%, $\mathrm{n}=48 / 105)$ compared with the monofocal IOL group $(2.1 \%, \mathrm{n}=2 / 97$; odds ratio, 45.9 [95\% confidence interval, 10.5 to 200.8]; $P<.0001$; Figure 2). Uncorrected distance visual acuity of $20 / 40$ or better at 6 months was achieved by $92 \%$ of patients in the multifocal IOL group and $97 \%$ of patients in the monofocal IOL 


\section{TABLE 2}

Vision-Related Quality of Life

\begin{tabular}{|c|c|c|c|c|c|c|c|}
\hline \multirow[b]{2}{*}{ Characteristic } & \multicolumn{2}{|c|}{ Multifocal Group $(n=108)$} & \multicolumn{2}{|c|}{ Monofocal Group $(n=98)$} & \multicolumn{3}{|c|}{ Between-Group Difference ${ }^{a}$} \\
\hline & No. & LS Mean (SE) & No. & LS Mean (SE) & LS Mean (SE) & $95 \% \mathrm{Cl}$ & $\boldsymbol{P}$ \\
\hline \multicolumn{8}{|l|}{ Primary endpoints } \\
\hline Activity limitations & 99 & $95.2(1.4)$ & 90 & $94.9(1.5)$ & $0.3(1.8)$ & -3.2 to 3.84 & .8515 \\
\hline Dependence on correction & 99 & 83.7 (3.5) & 92 & $46.3(3.7)$ & $37.3(4.4)$ & 28.7 to 46.0 & $<.0001$ \\
\hline Satisfaction with correction & 98 & $84.8(2.1)$ & 90 & $82.4(2.2)$ & $2.4(2.6)$ & -2.7 to 7.5 & .7040 \\
\hline \multicolumn{8}{|l|}{ Exploratory endpoints } \\
\hline Clarity of vision & 99 & $83.2(2.2)$ & 93 & $85.2(2.3)$ & $-2.1(2.8)$ & -7.5 to 3.4 & .4601 \\
\hline Expectations & 100 & $69.1(4.0)$ & 93 & $54.2(4.3)$ & $14.9(5.1)$ & 4.8 to 24.9 & .0039 \\
\hline Far vision & 100 & $85.0(1.8)$ & 93 & $88.2(1.9)$ & $-3.2(2.2)$ & -7.6 to 1.1 & .1436 \\
\hline Symptoms & 100 & $82.1(2.0)$ & 93 & $79.4(2.1)$ & $2.7(2.5)$ & -2.3 to 7.7 & .2839 \\
\hline Worry & 99 & $76.4(3.4)$ & 92 & $74.4(3.6)$ & $2.0(4.2)$ & -6.4 to 10.4 & .6400 \\
\hline Suboptimal correction & 97 & $96.4(1.5)$ & 90 & $97.8(1.5)$ & $-1.4(1.8)$ & -5.0 to 2.2 & .4552 \\
\hline
\end{tabular}

group. The number of patients with spectacle independence at 6 months was significantly higher in the multifocal IOL group than in the monofocal IOL group $(73.3 \%$ [ $n=74$ of 101$]$ vs $25.3 \%$ [ $n=24$ of 95 ], respectively; odds ratio, 10.2 [95\% confidence interval, 5.0 to 20.8; $P<.0001$; Figure 2). At 6 months, scores on the NEI RQL-42 survey for dependence on correction were significantly better in the multifocal IOL group (least squares mean \pm standard error, $83.7 \pm 3.5$ ) compared with the monofocal IOL group $(46.3 \pm 3.7 ; P<.0001)$. Scores were similar between treatment groups for the domains of near vision, activity limitations, appearance, and satisfaction with correction (Table 2).

The total cost of spectacles, the secondary endpoint, was significantly lower in the multifocal IOL group than in the monofocal IOL group $(P<.0001$; KolmogorovSmirnov test statistic, 0.49; Table A, available in the online version of this article). Total spectacle cost among all evaluable patients, including those who were spectacle independent, and in spectacle-dependent patients who reported spectacle cost information, was lower in the multifocal IOL group compared with the monofocal IOL group (Table A). The individual costs of lenses and frames were also lower with multifocal versus monofocal IOLs (Table A). Long-term costs were not determined.

Among the eight nonprimary NEI RQL-42 dimensions assessed as exploratory endpoints, patient scores for diurnal fluctuations, symptoms, worry, clarity of vision, far vision, and suboptimal correction were similar between groups. Scores (least squares mean \pm standard error) for patient expectations were significantly better in the multifocal IOL group (69.1 \pm 4.0$)$ compared with the monofocal IOL group ( $54.2 \pm 4.3 ; P<.01$; Table 2). Scores on the glare dimension were significantly better in the monofocal IOL group $(78.5 \pm 3.3)$ than in the multifocal IOL group $(69.0 \pm 3.1)(P<.05)$.

\section{SAFETY}

Treatment-emergent adverse events were reported for $40.6 \%$ (43 of 106) of patients in the multifocal IOL group and for $30.0 \%$ (30 of 100) of patients in the monofocal IOL group (Table B, available in the online version of this article). With the exception of two events (right and left eye) of photophobia reported in 1 patient in the monofocal IOL group, adverse events and serious adverse events were considered to be unrelated to the study devices. Posterior capsule opacification was observed in 5 patients who received multifocal IOLs and in 3 patients who received monofocal IOLs; surgical reintervention (ie, YAG capsulotomy) was required for 3 eyes in the multifocal IOL group. The optic disc edge of the multifocal and monofocal IOLs is identical; thus, the higher frequency of posterior capsule opacity in the multifocal group was not related to its shape. 
Furthermore, rates of posterior capsule opacification were not significantly different between the monofocal and multifocal IOL groups. As described above, selfreported scores for glare were worse in the multifocal IOL group compared with the monofocal group.

At the 6-month visit, $75.5 \%$ (160 of 212 ) of eyes in the multifocal IOL group and $77.7 \%$ (153 of 197) of eyes in the monofocal IOL group achieved a refraction outcome within $0.5 \mathrm{D}$ of target refraction. In the multifocal group, $81.1 \%$ received toric IOLs (86 of 106). The percentage of eyes within $1.0 \mathrm{D}$ of target refraction was $91.0 \%$ and $91.4 \%$ for the multifocal and monofocal groups, respectively. Refraction was measured as sphere plus ( $0.5 \times$ cylinder), with the target being zero.

\section{DISCUSSION}

The standard of care for treatment of cataract involves removal of the crystalline lens and subsequent implantation of a nontoric monofocal IOL. Despite improvements in surgical techniques and outcomes, patients often require multifocal spectacles for near visual acuity and residual astigmatic error after surgery. ${ }^{3}$ Postoperative dependence on vision correction is one of several factors that contribute to diminished vision-related quality of life after cataract surgery. The goal of this study was to evaluate and compare visual outcomes, spectacle independence, and quality of life among nonastigmatic and astigmatic patients who received AcrySof IQ ReSTOR toric or nontoric multifocal IOLs compared with those who received commercially available monofocal IOLs following bilateral cataract removal.

In this study, both toric and nontoric AcrySof multifocal IOLs were effective and well tolerated. Compared with patients who received bilateral nontoric monofocal IOLs, patients who received either nontoric or toric multifocal IOLs had a significantly higher rate of improved combined uncorrected near and distance visual acuity in both eyes, a significantly higher rate of spectacle independence, and significantly better NEI RQL-42 scores for dependence on correction. There was also a significant difference in postoperative spectacle cost that favored the multifocal IOL group versus the monofocal IOL group. The rates of adverse events and the proportions of patients achieving postoperative spherical equivalent within 0.5 and $1.0 \mathrm{D}$ of target refraction 6 months after surgery and IOL implantation were similar between groups.

The results of the current study are consistent with those of a prospective, 6-month follow-up study of patients in Europe and South America who received bilateral AcrySof aspheric toric or nontoric multifocal IOLs after cataract extraction. ${ }^{13}$ In that study, patients' subjective experience, satisfaction, and spectacle freedom were significantly improved with implantation of multifocal IOLs. After 6 months, 90\% of patients reported no spectacle dependence, ${ }^{13}$ compared with approximately $73 \%$ of patients in the current study. Similarly, multifocal IOLs produced significant improvements in uncorrected visual acuity compared with preoperative levels ${ }^{13}$ and monofocal IOLs, respectively. Our results also demonstrated that predictability of refractive outcome was similar between groups, indicating that the higher rate of postoperative spectacle dependence in patients who received monofocal IOLs could be attributed to a poor ability to focus across a range of distances, whereas patients who received multifocal IOLs had improved vision at far, intermediate, and near distances.

Lower contrast sensitivity and higher incidence of photic phenomena, such as halos and glare, have been reported with multifocal IOLs compared with monofocal IOLs, ${ }^{3,10}$ despite good vision over a range of distances and spectacle independence achieved with multifocal IOLs. ${ }^{14,15}$ At the 1-year follow-up visit of a randomized prospective clinical trial, halo and glare were reported to be more common with refractive multifocal IOLs compared with diffractive IOLs, and contrast sensitivity in patients with diffractive multifocal IOLs was similar or superior to that in patients who received monofocal IOLs or refractive multifocal IOLs. ${ }^{14}$ However, similar to the current study, implantation with diffractive multifocal IOLs was associated with greater spectacle independence. The findings of the current study demonstrated significantly higher incidence of glare with multifocal IOLs compared with monofocal IOLs, although the difference was only approximately $14 \%$, suggesting a clinically relevant complication for both groups. Despite the increased glare, patient satisfaction was high in the multifocal IOL group.

Using a combination of clinical observations and modeling, studies conducted in Europe previously showed that patients receiving AcrySof multifocal IOLs achieved higher rates of spectacle independence, and therefore postoperative lower cost burdens, compared with patients who received monofocal IOLs. ${ }^{7,16}$ An open-label multicenter study of U.S. patients similarly found that multifocal IOLs lead to higher rates of spectacle independence than monofocal IOLs; this work also estimated a net 14-year cost benefit of nearly $\$ 12,000$ (U.S.) with multifocal IOLs compared with $\$ 155$ with monofocal IOLs. ${ }^{4}$ In the current study, the total cost of spectacles was significantly higher in the monofocal IOL group, with costs for lenses alone nearly $75 \%$ higher than in the multifocal IOL group. 
This was likely because patients who received monofocal IOLs required higher technology lenses such as bifocals to provide good vision at different distances. Together with the better score in the dimension of dependence on correction in the multifocal IOL group, these data suggest that AcrySof multifocal IOLs could provide a long-term cost benefit for patients after cataract surgery.

Toric IOLs were available to patients with astigmatism receiving multifocal IOLs. At the time of the trial, no computerized devices were available for multifocal toric IOL alignment. In our experience with patients implanted with multifocal toric IOLs, spectacle independence is closely related to IOL alignment. With the availability of newer technologies that optimize alignment and centration of multifocal toric IOLs, post-implantation outcomes may be even better than those observed in the current study. A limitation of this study is the need for a more detailed analysis of efficacy and safety outcomes in patients receiving toric versus nontoric IOLs and in patients receiving multifocal versus monofocal toric IOLs. Patients in the monofocal group received only nontoric IOLs; as such, visual outcomes may have been influenced by uncorrected astigmatism in these patients. However, this influence may have been negligible because uncorrected distance visual acuity of $20 / 40$ or better at 6 months was achieved by $92 \%$ of patients receiving multifocal IOLs and by $97 \%$ of patients receiving monofocal IOLs. Additionally, cost assessments accounted only for postoperative spectacle costs; the costs associated with premium versus standard IOLs were not addressed. No adjustment was made for multiple testing correction for nonprimary endpoints. In some instances the questionnaires were not reviewed for completeness, which resulted in responses being ambiguous or missing. Methods for dealing with missing data were prespecified in the statistical analysis plan, and data handling conventions were defined to best accommodate instances where more than one response was entered for each question.

Patients with or without astigmatism and who received nontoric or toric AcrySof IQ ReSTOR IOLs following phacoemulsification cataract removal had significantly better visual acuity response rates and better overall vision-related quality of life (eg, spectacle independence, dependence on correction) compared with patients who received nontoric monofocal IOLs. Monofocal IOLs were associated with better patient-reported scores for glare compared with multifocal IOLs; however, scores for patient expectations were significantly better in the multifocal IOL group. Both the multifocal and monofocal IOLs were well tolerated.

\section{AUTHOR CONTRIBUTIONS}

Data collection ( $C P-M, T R, S S, P V)$; analysis and interpretation of data (CP-M, SS, $P V$ ); writing the manuscript (SS); critical revision of the manuscript (CP-M, TR, SS, PV); supervision (CP-M, TR)

\section{REFERENCES}

1. Congdon N, Vingerling JR, Klein BE, et al. Prevalence of cataract and pseudophakia/aphakia among adults in the United States. Arch Ophthalmol. 2004;122:487-494.

2. Lundstrom M, Barry P, Henry Y, Rosen P, Stenevi U. Evidencebased guidelines for cataract surgery: guidelines based on data in the European Registry of Quality Outcomes for Cataract and Refractive Surgery database. J Cataract Refract Surg. 2012;38:1086-1093.

3. Calladine D, Evans JR, Shah S, Leyland M. Multifocal versus monofocal intraocular lenses after cataract extraction. Cochrane Database Syst Rev. 2012;9:CD003169.

4. Maxwell WA, Waycaster CR, D’Souza AO, Meissner BL, Hileman K. A United States cost-benefit comparison of an apodized, diffractive, presbyopia-correcting, multifocal intraocular lens and a conventional monofocal lens. J Cataract Refract Surg. 2008;34:1855-1861.

5. Rubenstein JB, Raciti M. Approaches to corneal astigmatism in cataract surgery. Curr Opin Ophthalmol. 2013;24:30-34.

6. Alio JL, Plaza-Puche AB, Pinero DP, Amparo F, RodriguezPratz JL, Avala MJ. Quality of life evaluation after implantation of 2 multifocal intraocular lens models and a monofocal model. J Cataract Refract Surg. 2011;37:638-648.

7. de Vries NE, Laurendeau C, Lafuma A, Berdeaux G, Nuijts RM. Lifetime costs and effectiveness of ReSTOR compared with a monofocal IOL and Array-SA40 in the Netherlands. Eye (Lond). 2010;24:663-672.

8. Fisher BL. Presbyopia-correcting intraocular lenses in cataract surgery-a focus on ReSTOR® intraocular lenses. US Ophthalmic Review. 2011;4:44-48.

9. Ji J, Huang X, Fan X, Luo M. Visual performance of Acrysof ReSTOR compared with a monofocal intraocular lens following implantation in cataract surgery. Exp Ther Med. 2013;5:277-281.

10. Peng C, Zhao J, Ma L, Qu B, Sun Q, Zhang J. Optical performance after bilateral implantation of apodized aspheric diffractive multifocal intraocular lenses with +3.00-D addition power. Acta Ophthalmol. 2012;90:e586-e593.

11. Hays RD, Mangione CM, Ellwein L, Linblad AS, Spritzer KL, McDonnell PJ. Psychometric properties of the National Eye Institute-Refractive Error Quality of Life instrument. Ophthalmology. 2003;110:2292-2301.

12. McAlinden C, Skiadaresi E, Moore J, Pesudovs K. Subscale assessment of the NEI-RQL-42 questionnaire with Rasch analysis. Invest Ophthalmol Vis Sci. 2011;52:5685-5694.

13. Knorz MC, Rincon JL, Suarez E, et al. Subjective outcomes after bilateral implantation of an apodized diffractive +3.0 D multifocal toric IOL in a prospective clinical study. J Refract Surg. 2013;29:762-767.

14. Cillino S, Casuccio A, Di Pace F, et al. One-year outcomes with new-generation multifocal intraocular lenses. Ophthalmology. 2008;115:1508-1516

15. Cochener B, Lafuma A, Khoshnood B, Courouve L, Berdeaux G. Comparison of outcomes with multifocal intraocular lenses: a meta-analysis. Clin Ophthalmol. 2011;5:45-56.

16. Lafuma A, Berdeaux G. Modelling lifetime cost consequences of ReSTOR in cataract surgery in four European countries. BMC Ophthalmol. 2008;8:12. 


\section{TABLE A}

\section{Postoperative Spectacle Cost}

\begin{tabular}{|c|c|c|}
\hline Cost (Euros) & Monofocal Group $(\mathbf{n}=98)$ & Multifocal Group ( $n=108$ ) \\
\hline \multicolumn{3}{|c|}{ Total cost of spectacles (lenses + frames) } \\
\hline \multicolumn{3}{|l|}{ All patients } \\
\hline No. & 101 & 95 \\
\hline Mean \pm standard deviation & $151.50 \pm 236.84$ & $40.12 \pm 111.80$ \\
\hline Median & 85.73 & 0.00 \\
\hline \multicolumn{3}{|l|}{ Spectacle-dependent patients ${ }^{a}$} \\
\hline No. & 55 & 19 \\
\hline Mean \pm standard deviation & $224.41 \pm 276.86$ & $178.36 \pm 203.99$ \\
\hline Median & 117.95 & 96.00 \\
\hline \multicolumn{3}{|l|}{ Lenses $^{a}$} \\
\hline No. & 32 & 13 \\
\hline Mean \pm standard deviation & $267.21 \pm 258.26$ & $154.42 \pm 170.13$ \\
\hline Median & 170.00 & 90.00 \\
\hline \multicolumn{3}{|l|}{ Frames $^{a}$} \\
\hline No. & 27 & 10 \\
\hline Mean \pm standard deviation & $74.35 \pm 84.79$ & $66.59 \pm 103.70$ \\
\hline Median & 45.00 & 25.25 \\
\hline
\end{tabular}




\begin{tabular}{|c|c|c|}
\hline \multicolumn{3}{|c|}{$\begin{array}{c}\text { TAB } \angle E B \\
\text { Adverse Events }\end{array}$} \\
\hline Characteristic & $\begin{array}{l}\text { Multifocal Group } \\
(n=106)\end{array}$ & $\begin{array}{c}\text { Monofocal Group } \\
(n=100)\end{array}$ \\
\hline $\begin{array}{l}\text { No. of patients with } \geq 1 \\
\text { AEs (\%) }\end{array}$ & $43(40.6)$ & $30(30.0)$ \\
\hline Total no. of AEs & 73 & 77 \\
\hline $\begin{array}{l}\text { No. of patients with } \geq 1 \\
\text { serious } A E(\%)\end{array}$ & $13(12.3)$ & $9(9.0)$ \\
\hline \multicolumn{3}{|l|}{ No. of serious AEs (\%) } \\
\hline $\begin{array}{l}\text { Posterior capsule } \\
\text { opacification }\end{array}$ & $2(1.9)$ & 0 \\
\hline Astigmatism & $1(0.9)$ & 0 \\
\hline Corneal edema & $1(0.9)$ & 0 \\
\hline Cystoid macular edema & $1(0.9)$ & 0 \\
\hline Lens dislocation & $1(0.9)$ & 0 \\
\hline Retinal tear & $1(0.9)$ & 0 \\
\hline Vitreous loss & $1(0.9)$ & 0 \\
\hline Leukemia & $1(0.9)$ & 0 \\
\hline Cardiac disorder & $1(0.9)$ & 0 \\
\hline $\begin{array}{l}\text { Intestinal functional } \\
\text { disorder }\end{array}$ & $1(0.9)$ & 0 \\
\hline Endophthalmitis & $1(0.9)$ & 0 \\
\hline $\begin{array}{l}\text { Intraocular pressure } \\
\text { increased }\end{array}$ & $1(0.9)$ & 0 \\
\hline Nephrolithiasis & $1(0.9)$ & 0 \\
\hline Iridocele & 0 & $1(1.0)$ \\
\hline Photophobia & 0 & $1(1.0)$ \\
\hline Retinal detachment & 0 & $1(1.0)$ \\
\hline Vitreous detachment & 0 & $1(1.0)$ \\
\hline Vitritis & 0 & $1(1.0)$ \\
\hline Malignant lung neoplasm & 0 & $1(1.0)$ \\
\hline Neuroma & 0 & $1(1.0)$ \\
\hline Device material issue & 0 & $1(1.0)$ \\
\hline $\begin{array}{l}\text { Eye operation } \\
\text { complication }\end{array}$ & 0 & $1(1.0)$ \\
\hline COPD & 0 & $1(1.0)$ \\
\hline \multicolumn{3}{|c|}{$\begin{array}{l}A E=\text { adverse event; monofocal group = commercially available nontoric } \\
\text { monofocal intraocular lens group; multifocal group = AcrySof IQ ReSTOR } \\
\text { or AcrySof IQ ReSTOR toric intraocular lens (Alcon Laboratories, Fort Worth, } \\
\text { TX) group; COPD = chronic obstructive pulmonary disease }\end{array}$} \\
\hline
\end{tabular}

